\title{
Reasons for reported suspicion of child maltreatment and responses from the child welfare - a cross-sectional study of Norwegian public dental health personnel
}

Ingfrid Vaksdal Brattabø $\varnothing^{1,2^{*}}$, Ragnhild Bjørknes ${ }^{2}$ and Anne Nordrehaug Åstrøm ${ }^{1,3}$

\begin{abstract}
Background: To prevent child maltreatment, the identification of vulnerable children is essential. In Norway, public dental health personnel (PDHP) report suspicion of child maltreatment to child welfare services (CWS) at a relatively high rate. However, their reasons for reporting and the response from CWS have not been investigated. The objectives of this study were to (1) explore the reasons that PDHP send reports of concern, (2) examine how CWS responds to PDHP reports, and (3) assess whether different reasons for concern are associated with a given response from CWS.

Methods: A national cross-sectional study was conducted by an electronic survey distributed to public dental hygienists and dentists in Norway. Descriptive statistics were calculated in terms of mean (SD) distributions and frequency, expressed as \% (n). To account for clustering of responses among respondents, binomial generalized estimating equation analysis was used to estimate odds ratios (ORs) and confidence intervals (Cls) of CWS responses across number of reports with different reasons for concern.

Results: Of a total of 1542 questionnaire recipients, 1200 (77.8\%) responded to the survey. From 2012 to 2014, 42.5\% of the respondents sent 1214 reports to CWS, with a mean number of $2.7(S D=2.0)$ reports per respondent. The PDHP sent the reports due to suspicion of neglect or physical, sexual and/or psychological abuse. Non-attendance at dental appointments and grave caries were reported most frequently. Among the reports, 24.5\% resulted in measures being taken by CWS, 20.7\% were dropped, and 29.4\% lacked information from CWS on the outcome. Reports due to suspicion of sexual abuse, (OR 1. $979,95 \% \mathrm{Cl}(1.047-3.742), P=0.036)$, grave caries (OR 1.628, 95\% Cl (1.148-2.309), $P=0.006)$, and suspicion of neglect (OR 1. $649,95 \% \mathrm{Cl}(1.190-2.285), P=0.003)$ had the highest association with the implementation of measures.

Conclusions: PDHP report on several forms of child maltreatment and contributes in detection of victimized children. However, the relatively low number of measures being taken by CWS and the number of reports that lack a response to reporters reveal a need for a closer cooperation between the services, as this would benefit both the children at risk and the services.
\end{abstract}

Keywords: Child maltreatment, Child abuse, Dental neglect, Sexual abuse, Oral health, Caries, Mandatory reporting, Child welfare services, Dental health services, Dentist

\footnotetext{
* Correspondence: ingfrid.brattabo@hfk.no

${ }^{1}$ Oral Health Centre of Expertise in Western Norway/Hordaland, Pb. 2354,

Møllendal, 5867 Bergen, Norway

2Department of Health Promotion and Development, Faculty of Psychology,

University of Bergen, Pb. 7807, 5020 Bergen, Norway

Full list of author information is available at the end of the article
}

(c) The Author(s). 2018 Open Access This article is distributed under the terms of the Creative Commons Attribution 4.0 International License (http://creativecommons.org/licenses/by/4.0/), which permits unrestricted use, distribution, and reproduction in any medium, provided you give appropriate credit to the original author(s) and the source, provide a link to the Creative Commons license, and indicate if changes were made. The Creative Commons Public Domain Dedication waiver (http://creativecommons.org/publicdomain/zero/1.0/) applies to the data made available in this article, unless otherwise stated. 


\section{Background}

\section{Child maltreatment}

Being a victim of serious child maltreatment increases the risk of having developmental disturbances and reduces the possibility of having a normal and wholesome childhood. In fact, for many children, child maltreatment results in severe and lifelong challenges [1-3]. Child maltreatment is a widespread phenomenon worldwide [4]. There is a compelling body of research indicating that the maltreated children known to child welfare services (CWS) only represent the tip of the iceberg relative to the actual number of children being maltreated [4-7]. To prevent child maltreatment and its consequences, it is important to identify children at risk as well as children who are already victims. Such efforts require an interdisciplinary collaboration between the services working with children, and CWS is essential in this context.

\section{Mandatory reporting, the role of dental services and child welfare services}

Several countries have enacted legislation mandating reporting of maltreatment, with the goal of increasing the reporting frequency among designated personnel working with children [8-10]. Research has indeed shown an increase in reporting frequency as reporting becomes mandatory $[11,12]$.

All health personnel in Norway are mandated by the Norwegian Health Personnel Act, section $6 ₫ 33$, to report suspicion of severe child maltreatment to CWS [13]. The Norwegian public dental health service (PDHS) is mandated by the Dental Health Service Act to prioritize the prevention of dental disease and offer all children under the age of 19 free and regular dental treatments [14]. As a result, close to $100 \%$ of all children in Norway are regularly covered by the PDHS. This situation gives the PDHS an important and unique opportunity to detect and report suspicion of child maltreatment to CWS. Public dental health personnel (PDHP) in Norway are experienced reporters of child maltreatment, with a total of $60 \%$ having reported suspicion of child maltreatment to CWS during their career [15].

The assignment of the Norwegian CWS reflects the general reporting legislation and the fact that Norway is a social-democratic welfare state [16]. The CWS is mandated by the Child Welfare Act, section $6 ₫ 6-7 \mathrm{a}$, to provide a response to reporters within three weeks, although a response is not mandatory if the concern is clearly unsubstantiated. In cases for which an investigation has been opened, CWS provides the reporter with information on whether the case has been dropped or measures have been taken [17].

\section{Previous research}

Over the last decade, a number of studies have investigated the role of dental personnel in child maltreatment issues [15, 18-29]. High-quality research has focused on dental personnel, the frequency of reporting, failure to report, knowledge regarding child maltreatment and barriers to reporting [15, 18-20, 22, 24, 25, 28, 29]. However, little research has been focused on the reasons why dental personnel report to CWS $[26,30]$ and the associated responses from CWS. Additionally, to the best of our knowledge, no previous studies have explored how CWS responds to reports of concern from dental services and to what degree the Norwegian CWS fulfills the mandated response to designated reporters in this regard [17].

Although dental personnel's barriers to and limited knowledge regarding reporting have been recognized and targeted in recent decades, the gap between suspecting child maltreatment and reporting seems to persist, implying that researchers have not succeeded in exploring all of the problems related to mandatory reporting [31]. To enhance our understanding and knowledge of the mechanisms involved in mandatory reporting in dental services, it is important to examine dental personnel's reasons for sending a more thorough report of concern. Additionally, knowledge of how CWS responds to the different reports of concern sent by the PDHS should be obtained.

\section{Aims}

Focusing on a census of public dentists and dental hygienists in Norway, the objectives of this study were threefold. First, we assessed the reasons reported by PDHP for having sent a report of concern to CWS during the threeyear period from 2012 to 2014. Second, we examined how CWS responded to these reports. Third, we assessed whether the different reasons for sending a report of concern were associated with a given response from CWS.

\section{Methods}

\section{Study design and data collection}

This national cross-sectional study was conducted by an electronic survey in a census of dental health personnel employed by the PDHS in Norway. Specifically, an email explaining the purpose of the study and providing a link to the electronic questionnaire, also containing an informed consent form, were distributed to all dental hygienists and dentists. The chiefs of the PDHS provided the names and e-mail addresses of their employees and gave their employees permission to answer the survey questions during their working hours. The estimated time required to complete the questionnaire was 30-40 $\mathrm{min}$.

The survey contained questions regarding experience with suspecting and reporting child maltreatment, reasons for reporting and/or not reporting, experience with CWS, organizational questions regarding PDHS and the demographic characteristics of the respondents. A portion of the questions was derived from an Australian 
survey [32, 33], with certain necessary adjustments to tailor the questions to dental personnel in a Norwegian context. In particular, the questions from the Australian questionnaire were translated into Norwegian and then back translated into English to evaluate the semantic and content equivalence. The questionnaire was reviewed by PDHP with experience in survey research and clinical work at the PDHS before it was piloted among PDHP in one county. After certain small adjustments, the questionnaire was distributed to the 18 remaining counties in Norway. The Ombudsman, Norwegian Social Science Data Services (NSD), approved and registered the survey and was responsible for distributing the questionnaire and collecting the data. The main survey was distributed in November 2014, and follow-ups with reminders were sent to non-responders after two, four and seven weeks. The questionnaire is available in Norwegian, as an additional file (see Additional file 1).

\section{Variables and their measurement}

Experience with sending a report of concern to CWS was measured via the following question: 'During your time as dental personnel, have you filed a report of concern due to suspicion of child abuse or neglect?' The options were yes or no. Those answering yes were asked 'Were any of the reports of concern sent in the time period from 2012 to this day?' The response options were yes or no. If the respondent answered yes, they were asked 'How many concerns have you filed since 2012?' The response options ranged from one to ten or more concerns.

The respondents who had filed one or several reports of concern in the previous three years, from 2012 to 2014, were asked to provide the following information for each of the concerns that they reported having sent to CWS during this period: 'The following questions regard the first report of concern that you sent in 20122014. What was the gender of the child in the first report of concern that you sent?' The response options were boy or girl. 'What was the age of the child in the first report of concern that you sent?' The response options were $0-3,4-7,8-11,12-15$, and over 16 years. 'What was the reason for the first report of concern that you sent? Multiple categories can be chosen.' The response options were suspicion of physical abuse, suspicion of sexual abuse, suspicion of psychological abuse, suspicion of neglect, recurring missed appointment, grave caries, gingivitis, lack of hygiene, wounds and lesions in the oral cavity, trauma, other oral findings (please note), treatment refusal, cooperation with guardians, abnormal behavior, and other (please note). Wounds and lesions in the oral cavity and other oral findings were merged into one variable due to the low response frequency.
The background characteristics of the PDHP respondents that were assessed were gender, age (20-39 or 40+ years), occupation (dental hygienist or dentist), the number of patients treated in the last 12 months $(0-500$ or $501+$ patients), the size of the municipality $(0-10,000$, $10,001-40,000$, or $40,001+$ inhabitants) and the geographical region where the dental clinic was located (north, central, west, south or east). More detailed information on the background characteristics can be found in a study by Brattabø et al., 2016 [15].

Regarding the responses from CWS, the PDHP were asked the following: 'What response have you received from CWS regarding the first report of concern that you sent?' The response options were as follows: 'CWS has opened an investigation and taken measures,' 'CWS has opened an investigation but dropped the case, ' $\mathrm{CWS}$ has opened an investigation but has not given me any feedback on whether measures have been taken or the case has been dropped,' 'CWS has not opened an investigation, so the case has been dropped, ' $\mathrm{CWS}$ has not given any feedback,' 'Other (please note)', and 'Do not know'.

The question battery described above regarding the reports of concern and corresponding responses from CWS was administered to each respondent repeatedly, the same number of times (1-10) that they had reported having sent a report of concern during the 2012-2014 period. Only the number of the report of concern mentioned in the questions was changed: 'The following questions regard your [second, third, fourth, etc.] report of concern'.

\section{Statistical analysis}

Data were analyzed using the Statistical Package for Social Sciences version 22 (SPSS Inc., Chicago, IL, USA). Descriptive statistics, in terms of frequency \% (n) and mean (SD) distributions, were calculated. The frequency of the independent variables relative to the dependent variables was calculated using multiple responses, frequencies and cross tables. Due to the layout of the questionnaire and because each respondent could have sent up to ten reports of concern, variables were restructured from multiple variables to groups of related cases. Repeated data had a multilevel structure, with observations nested within individuals or clusters. To account for clustering in repeated data, responses from CWS were regressed on reasons for concern across the numbers of reports (first report of concern, second report of concern and so on) using the binomial generalized estimating equation (GEE) [34]. After restructuring the original data file from wide (number as a variable) to long (number as a case) configuration, the binomial logit function and exchangeable working correlation matrix were employed. CWS responses by reasons for concerns across number of reports were estimated using odds 
ratios (ORs) and 95\% confidence intervals (CIs). Both unadjusted and adjusted GEE analyses were performed, and the significance level was set to $P<0.05$.

For model building, a series of unadjusted and adjusted GEE models were fitted. Initial models were built by adding children's age and gender and the PDHP's specific occupation, number of patients treated, municipality size and geographical region in addition to the range of reasons for concern. As both the unadjusted and the adjusted analyses revealed no significant effect of gender, the age of the child, the number of patients treated, the size of the municipality or the geographical region, those variables were excluded from the final GEE model to strengthen the analysis. The final GEE model included occupation as the only background variable in addition to the range of reasons for concern, as mutually adjusted.

\section{Results}

\section{Characteristics of the respondents}

Of a total of 1542 questionnaire recipients, 1200 (77.8\%) dentists and dental hygienists responded to the survey. As previously described [15], most of the 1200 respondents were women (80.3\%) and dentists (68.9\%), reflecting the present situation of the PDHS labor market in Norway [35]. The respondents had a mean of $11.9(\mathrm{SD}=11.2)$ years of working experience, and $82.9 \%$ had examined more than 250 children under the age of 18 years during the previous 12 months. A total of $720(60 \%)$ respondents had filed a report of concern during their career, with a mean of $3.6(\mathrm{SD}=3.4)$ reports per experienced reporter, and $42.5 \%$ had filed a report during the three-year period from 2012 to 2014, with a mean number of 2.7 reports $(\mathrm{SD}=2.0)$ per experienced reporter.

In the 2012-2014 period, the respondents reported having sent 1214 reports of concern to CWS, with $55.9 \%$ of the reports of concern regarding boys. The children had the following age distribution: $6.8 \%$ of the children were under the age of four, $35.6 \%$ were between 4 and 7 years, 31.6\% were between 8 and 11 years, 20.5\% were between 12 and 15 years, and 5.6\% were between 16 and 17 years. Therefore, $74 \%$ of the children were under the age of 12 years.

\section{Reasons for concern}

As shown in Table 1, the majority of the 2012-2014 reports of concern from PDHP were sent to CWS for multiple reasons, with a mean of $2.7(\mathrm{SD}=1.8)$ reasons for concern per report. The most frequently reported reason for concern was 'did not attend dental appointment', which was cited in $67.4 \%$ of the reports. Grave caries was reported in nearly half of the reports of concern (49.2\%), and lack of hygiene and suspicion of neglect were reported in $36.7 \%$ and $25.9 \%$ of the cases, respectively. Suspicion of physical abuse, sexual abuse
Table 1 Reasons for sending reports of concern to CWS among PDHP in Norway, 1214 reports of concern, 3222 reasons for concern

\begin{tabular}{lll}
\hline Reason for sending a report of concern & $n$ & \% of reports \\
\hline Did not attend/was not brought & 818 & 67.4 \\
Grave caries & 597 & 49.2 \\
Lack of hygiene & 445 & 36.7 \\
Suspicion of neglect & 315 & 25.9 \\
Interaction with parents/guardians & 232 & 19.1 \\
Abnormal behavior in the child & 220 & 18.1 \\
Treatment refusal & 205 & 16.9 \\
Gingivitis & 119 & 9.8 \\
Suspicion of physical abuse & 59 & 4.9 \\
Suspicion of sexual abuse & 57 & 4.7 \\
Suspicion of psychological abuse & 53 & 4.4 \\
Trauma & 20 & 1.6 \\
Wounds, lesions or other oral findings & 14 & 1.2 \\
Other & 68 & 5.6 \\
\hline
\end{tabular}

The frequencies do not sum to $100 \%$ due to multiple reasons for concern

and/or psychological abuse was cited in $4.9 \%, 4.7 \%$ and $4.4 \%$ of the reports, respectively.

\section{Frequency distribution of responses given by CWS to PDHP's reports of concern}

Different responses were provided by CWS to the reports of concern sent by the PDHP during the period from 2012 to 2014. Summing the first three columns depicted in Table 2, related to the cases in which CWS had opened an investigation and had taken measures, dropped the case or had not given any further information, revealed that $51.1 \%$ of the reports sent to CWS resulted in an investigation. Meanwhile, $4.6 \%$ of the reports were dropped without any investigation, and no feedback or information has been provided to the PDHP by CWS for $18.9 \%$ of the reports. Regarding the overall outcome from the PDHP reports of concern, $24.5 \%$ of reports of concern led to measures being taken by CWS, $20.7 \%$ of reports were dropped either after investigation or immediately, and CWS did not provide information on the outcome of the investigation or at all in $29.4 \%$ of

Table 2 Frequency distribution of responses of CWS to reports of concern (1214) sent by PDHP in 2012-2014

\begin{tabular}{lll}
\hline Response from CWS & $n$ & $\%$ \\
\hline CWS has opened an investigation and taken measures & 297 & 24.5 \\
CWS has opened an investigation and dropped the case & 195 & 16.1 \\
CWS has opened an investigation, but no further information & 127 & 10.5 \\
has been given & 56 & 4.6 \\
CWS has not opened an investigation, case dropped & 229 & 18.9 \\
CWS has not given any feedback at all & 310 & 25.5 \\
\hline
\end{tabular}


reports. For the remaining $25.5 \%$ of reports, the dental personnel did not know or remember the outcome of their report of concern. Hence, the response estimates in Table 2 should be considered as minimum rates of occurrence.

\section{Reasons for sending report of concern and associated responses from CWS}

Table 3 provides an overview of the numbers of times different reasons for concern were reported across various responses from CWS. The different reasons for concern led to initiatives by CWS with frequencies ranging from 19.1-40.4\%. The reasons for concern that most frequently led CWS to open an investigation and take measures regarded suspicion of sexual abuse, trauma, suspicion of neglect and suspicion of physical abuse, with initiatives in response to $40.4 \%, 40.0 \%, 35.6 \%$ and $35.6 \%$ of the reports, respectively, in which reasons for concern were included. Furthermore, among a total of 818 reports of concern including the reason 'did not attend', only $21.4 \%$ resulted in initiatives by CWS; this reason for concern, together with wounds, lesions and other oral findings, led to the fewest initiatives by CWS. Reports of concern that included trauma or 'did not attend' were thus investigated and then dropped most frequently (accounting for 20.0\% and $17.2 \%$ of cases, respectively).

\section{Responses from CWS according to PDHP's reasons for sending report of concern}

Table 4 depicts the results from adjusted GEE analyses, with each response from CWS regressed upon PDHP's reasons of concerns across the number of reports. Each reason for concern was mutually adjusted for all other reasons for concern and for the PDHP's specific occupation (a background factor). As shown, dental personnel sending reports of concern due to missed appointments were less likely to have their reports opened and substantiated by CWS than their counterparts sending reports without this reason (OR 0.667, 95\% CI (0.4690.949), $P=0.024)$. Dental personnel sending reports of concern that included suspicion of sexual abuse (OR $1.979,95 \% \mathrm{CI}(1.047-3.742), P=0.036)$, grave caries (OR $1.628,95 \%$ CI (1.148-2.309), $P=0.006)$, or suspicion of neglect (OR 1.649, 95\% CI (1.190-2.285), $P=0.003)$ had a higher likelihood of having their reports opened and substantiated compared with dental personnel sending reports of concern without any of those reasons. Finally, reports of concern sent by dentists had a lower likelihood of being opened and substantiated compared with reports sent by dental hygienists (OR 0.623, 95\% CI (0.425-0.916), $P=0.016$ ).

Dental personnel sending reports of concern due to the abnormal behavior of the child were less likely to have their reports opened and then dropped (OR 0.498,
95\% CI (0.284-0.847), $P=0.015)$, and more likely to have their reports opened without being given any further information by CWS (OR 1.779, 95\% CI (1.0253.088), $P=0.041)$ compared with their counterparts sending reports of concern without this reason.

\section{Discussion}

The objectives of the present study were to explore PDHP's reasons for sending a report of concern in the three-year period from 2012 to 2014, to assess how CWS responded to the reports of concern and to examine whether the different reasons for concern were associated with a given response from CWS. This study showed that Norwegian PDHP report on several types of suspected child maltreatment, including neglect and physical, psychological and sexual abuse. Thus, the majority of reports were sent due to multiple reasons for concern. Only one-fourth of the reports from the Norwegian PDHS led to a measure being taken and the PDHP lacked information regarding the outcome in approximately one third of the reports, while one-fifth were dropped either directly or after investigation. Reports due to suspicion of sexual abuse, grave caries and suspicion of neglect were most strongly associated with a response from the CWS in terms of having opened an investigation and implemented measures.

The most frequently reported reasons for concern were repeated failure to attend dental appointments, grave caries, a lack of hygiene and suspicion of neglect which is in accordance with findings in a Swedish study [30]. Repeated failure to dental attendance, could be attributed to forgetting, an address change, a lack of time, illness or dental anxiety [36-38]. This finding indicates also that PDHP and the PDHS are alerted when children continuously forfeit their legal right to free dental care according to the Public Dental Health Service Act [14]. In addition, when children repeatedly fail to attend their dental appointments, PDHP are placed in a position in which they are unable to fulfill their obligation to determine whether there is a need for dental treatment or oral health guidance. Previous studies have demonstrated associations of failure to attend a dental appointment, an absence of dental care routines, caries and poor dental health with families struggling with their everyday life and children having adverse childhood experiences [30, 36, 39-43]. This implies that that continuously missed dental appointments and dental neglect could be indicators of child maltreatment and could be used as a tool for the early identification of struggling children and families.

In the present study, children of all ages were reported to CWS, with close to three-quarters being under the age of 12 years. These findings indicate that dental personnel are in a position to detect children at risk 


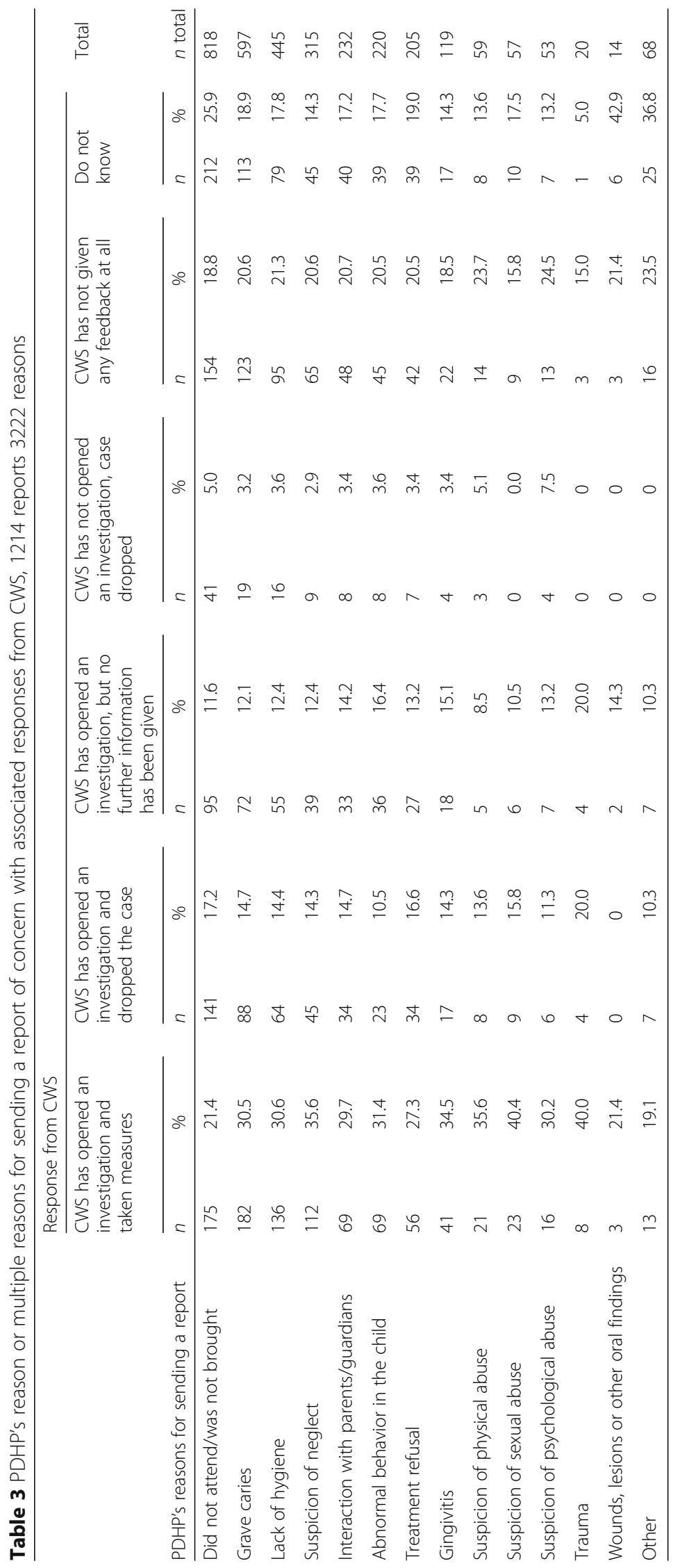




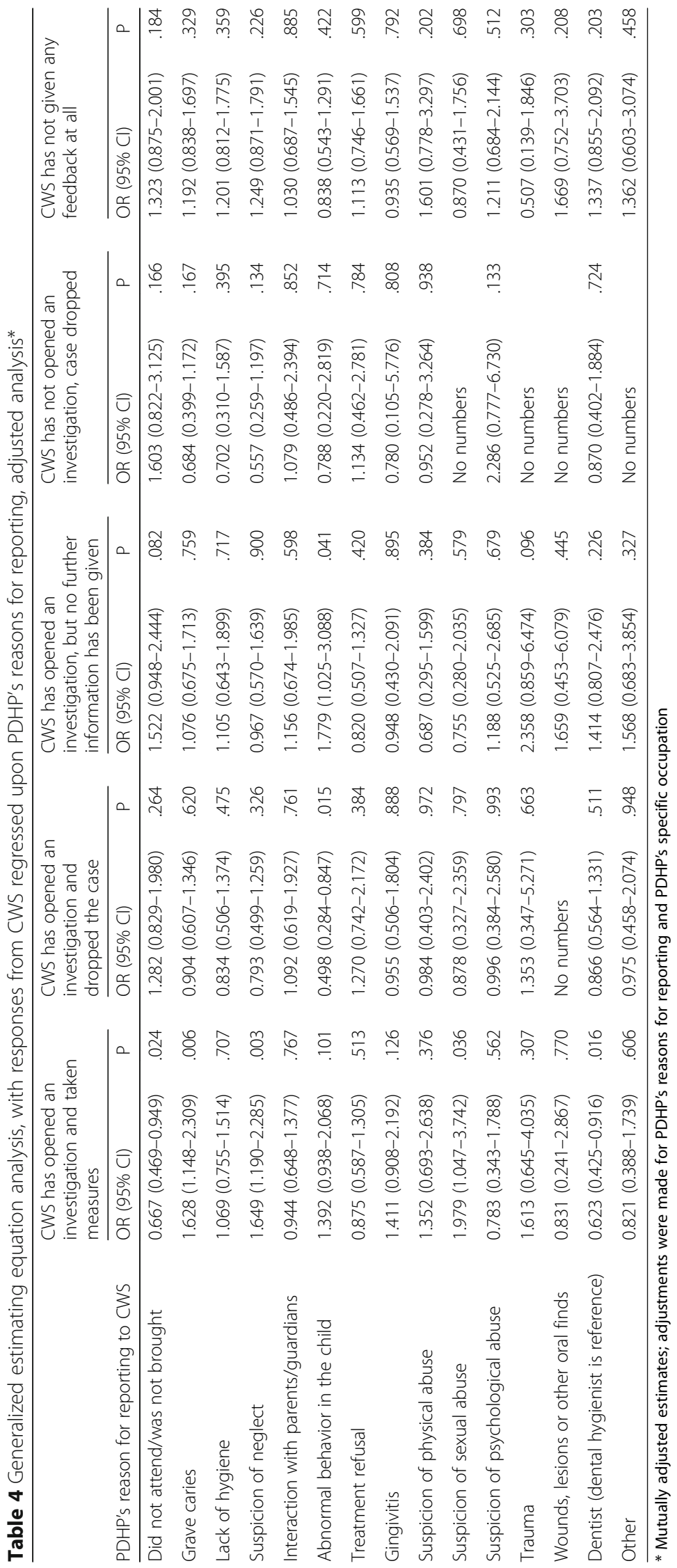


especially those at a younger age. Concerning early detection of vulnerable children, this finding is of particular importance.

Regarding the reports of concern due to grave caries, it is important to be aware that recent statistics in Norway reveal that $82 \%$ of 5 -year-olds and $60 \%$ of 12 year-olds had no experience with caries [35]. The good oral health of the majority of Norwegian children increases the conspicuousness of the children with extensive oral health problems. The present study suggests that PDHP are concerned for their patients with oral health deficiencies and suspect that these children may be neglected.

The results of the present study indicate competence and awareness among PDHP in Norway regarding the different forms of child maltreatment, even though potential cases of physical, psychological and sexual abuse were rarely reported. Increased focus during the recent years on child maltreatment-related issues in the PDHS, educational institutions, the media and among the authorities may be contributing factors in this regard. Present findings differ somewhat from findings in Sweden, where all the reports from dental service regarded concerns due to parental deficiencies (failure to attend appointments) and neglect (dental neglect), while concerns due to suspicion of psychological, sexual and/ or physical abuse were absent [30]. However, the present findings are partly in accordance with findings from Greece, where dentists suspected several forms of child maltreatment, although they had very low reporting frequency [26]. In addition, studies from Denmark, the UK and Scotland have also shown that dental personnel reports child abuse and neglect, although without specifying what kind of child abuse and neglect is being reported [19, 20, 22]. The discrepancy with previous studies could be due to differences in sample size and study design. Small sample sizes reduces the chance of rare concerns being detected. Further, due to recall biases, social desirability, differences in definitions, reporting and registration there might be discrepancy between studies based upon self-reports and case-reports.

Only one-fourth of the reports from the Norwegian PDHS led to a measure being taken. Moreover, the PDHP lacked information regarding the outcome in approximately one third of the reports while one-fifth were dropped either directly or after investigation. This might be attributed to large workload of CWS as the numbers from Statistics Norway reveal a general increase in reports to CWS over the last few years [44]. Other plausible explanations might be overreporting or insufficient reports of concern from PDHP [45, 46]. One might further wonder if the frequency of measures being taken and the lack of information to PDHP is a result of unclear response procedures within CWS or lack of knowledge within CWS regarding dental neglect and its consequences. Specifically, in light of the good oral health in Norwegian children, it might be difficult for a CWS worker to fully understand the consequences that a lack of oral hygiene and treatment could have for a child. At present, however, this is only speculation, so additional research is needed.

According to the present findings, the odds of an investigation being opened and measures taken was $98 \%$ higher for reports of concern due to suspicion of sexual abuse compared with reports not due to this suspicion. Furthermore, suspicion of neglect and grave caries also showed increased odds of $65 \%$ and $63 \%$, respectively for cases being opened and measures taken. The present findings suggest that CWS consider these concerns the most serious. In contrast, non-attendance at dental appointments seemed to be recognized as less serious reasons, with 33\% lower odds of cases being opened and measures being taken compared with reports due to other suspicions. Hence, it may be reasonable to assume that CWS considers non-attendance more of an indication than a serious suspicion of child maltreatment. Meanwhile, reports including concern about abnormal behavior in the child had 50\% lower odds of being dropped when first opened compared with reports without behavioral concerns, implying that CWS takes the behavior of children seriously. This study further show that, with the exception of abnormal behavior, no reason for concern was significantly associated with a case being dropped immediately or after investigation, which might indicate that CWS considers all types of reports from the PDHP.

The current findings might indicate that PDHP need to improve their reports of concern and clarify the severity of the consequences that a lack of oral hygiene and continuous missed appointments might have for a child. Furthermore, the present findings, with close to one third of the reports lacking information from CWS on the outcome, indicate that CWS should improve its feedback frequency to fulfill its obligation stemming from the Child Welfare Act. Overall, improvement of the cooperation and information flow between services will increase the knowledge of PDHP and CWS regarding the circumstances and needs of vulnerable children and will strengthen the wellbeing of these children.

For future research, there is a need to pinpoint whether continuously missed dental appointments and dental neglect are indicators of child maltreatment, serving as a tool for the early identification of struggling children and families. Furthermore, there is a need for research focusing on CWS and its experience with reports from and cooperation with PDHP. The present findings thus have implications for CWS, dental services, the authorities and future research. 
Certain limitations of the present study should be noted. First, the findings mainly rely on self-reports of PDHP, which may undermine the study of the responses. Data were not collected from CWS, and hence, the perspective and experiences of CWS regarding reports of concern coming from PDHP and the response of CWS to reporters are not reflected. Second, the present study builds upon the experiences and recollections of PDHP regarding their contact with CWS during the three previous years. Therefore, there is a possibility of recall bias. In contrast, reporting to CWS is a challenging and rare event for most PDHP, likely increasing the likelihood of recall.

\section{Conclusion}

This study shows that PDHP in Norway send reports to CWS regarding suspicion of the following different forms of child maltreatment: neglect and physical, sexual and/or psychological abuse. In general, PDHP reported that onefourth of their reports of concern resulted in a measure being taken by CWS. Reports of concern regarding suspicion of sexual abuse, suspicion of neglect and/or grave caries had the highest likelihood of being opened and measures being taken, whereas non-attendance at dental appointments had the lowest likelihood.

The present findings indicate that dental personnel are in position to detect several forms of child maltreatment. However, the relatively low number of measures being taken by CWS and the number of reports that lack a response to reporters imply that closer and enhanced cooperation between CWS and PDHS is needed. This would benefit both the children at risk, the PDHS and the CWS in Norway.

\section{Additional file}

Additional file 1: Tannhelse og barnevern - samhandling til beste for barnet. Questionnaire regarding dental personnel's suspicion of child maltreatment and reporting to child welfare services. The questionnaire was sent to dental hygienists and dentists in the public dental health service in Norway 2014. (PDF $254 \mathrm{~kb}$ )

\section{Abbreviations}

CWS: Child Welfare Service; GEE: Generalized Estimating Equations; NSD: Norwegian Social Science Data Services; PDHP: Public Dental Health Personnel; PDHS: Public Dental Health Service

\section{Acknowledgments}

The authors would like to express their gratitude to the respondents in the present study, including dental hygienists and dentists in the public dental health service in Norway.

\section{Funding}

This study did not receive any funding from agencies in the public, commercial, or not-for-profit sector.

\section{Availability of data and materials}

The dataset will not be made available, as more articles are to be published based on this dataset.

\section{Authors' contributions}

IVB: Contributed to the study design, was the main contributor to the data collection, carried out the statistical analysis and was the main contributor to writing the manuscript. RB: Contributed to the study design, data collection and writing of the manuscript. ANÅ: Contributed to the study design, statistical analysis and writing of the manuscript. All authors read and approved the final manuscript.

\section{Ethics approval and consent to participate}

The Regional ethics committee concluded that this study did not need an approval from the REK. The Ombudsman, Norwegian Social Science Data Services (NSD), approved and registered the survey. NSD was responsible for the questionnaire distribution and the data collection.

All participants received an email explaining the purpose of the study and informing them that all participation in this study was voluntary. The email included a link to the electronic questionnaire, which contained an informed consent form.

\section{Consent for publication}

Not applicable.

\section{Competing interests}

The authors declare that they have no competing interests.

\section{Publisher's Note}

Springer Nature remains neutral with regard to jurisdictional claims in published maps and institutional affiliations.

\section{Author details}

${ }^{1}$ Oral Health Centre of Expertise in Western Norway/Hordaland, Pb. 2354, Møllendal, 5867 Bergen, Norway. ${ }^{2}$ Department of Health Promotion and Development, Faculty of Psychology, University of Bergen, Pb. 7807, 5020 Bergen, Norway. ${ }^{3}$ Department of Clinical Dentistry, Faculty of Medicine and Dentistry, University of Bergen, Pb. 7804, 5020 Bergen, Norway.

Received: 6 July 2017 Accepted: 20 February 2018

Published online: 02 March 2018

\section{References}

1. Norman RE, Byambaa M, De R, Butchart A, Scott J, Vos T. The long-term health consequences of child physical abuse, emotional abuse, and neglect: a systematic review and meta-analysis. PLoS Med. 2012;9(11):1-31.

2. Gilbert R, Widom CS, Browne K, Fergusson D, Webb E, Janson S. Burden and consequences of child maltreatment in high-income countries. Lancet. 2009;373(9657):68-81.

3. Currie J, Widom CS. Child maltreatment 2010 best article award: long-term consequences of child abuse and neglect on adult economic well-being. Child maltreatment. 2011;16(3):233.

4. Stoltenborgh M, Bakermans-Kranenburg MJ, Alink LRA, van ljzendoorn MH. The prevalence of child maltreatment across the globe: review of a series of meta-analyses. Child Abuse Rev. 2015;24(1):37-50.

5. Stoltenborgh M, Bakermans-Kranenburg MJ, van ljzendoorn MH. The neglect of child neglect: a meta-analytic review of the prevalence of neglect. Soc Psychiatry Psychiatr Epidemiol. 2013;48(3):345-55.

6. Creighton SJ. Recognizing changes in incidence and prevalence. In: Browne KD, Hanks H, Stratton P, Hamilton C, editors. Early prediction and prevention of child abuse: A handbook. Chichester: Wiley; 2002. p. 5-22.

7. Euser S, Alink LRA, Pannebakker F, Vogels T, Bakermans-Kranenburg MJ, Van ljzendoorn MH. The prevalence of child maltreatment in the Netherlands across a 5-year period. Child Abuse Negl. 2013;37(10):841-51.

8. Mathews B, Kenny MC. Mandatory reporting legislation in the United States, Canada, and Australia: a cross-jurisdictional review of key features, differences, and issues. Child maltreatment. 2008;13(1):50-63.

9. Mathews B. Mandatory reporting laws: Their origin, nature, and development over time. In: Mandatory reporting laws and the identification of severe child abuse and neglect. edn. Heidelberg: Springer; 2015. p. 3-25. https://doi.org/10.1007/978-94-017-9685-9.

10. Daro D. World perspectives on child abuse. 7th ed. Chicago: International Society for Prevention of Child Abuse and Neglect; 2006. 
11. Mathews B, Lee XJ, Norman RE. Impact of a new mandatory reporting law on reporting and identification of child sexual abuse: a seven year time trend analysis. Child Abuse Negl. 2016;56:62-79.

12. Al Eissa M, Almuneef M. Child abuse and neglect in Saudi Arabia: journey of recognition to implementation of national prevention strategies. Child Abuse Negl. 2010;34(1):28-33.

13. The Health Personnel Act, [https://lovdata.no/dokument/NL/lov/1999-07-0264?q=helsepersonell\%20loven Accessed: 02.12.2016].

14. The Public Dental Health Service Act, [https://lovdata.no/dokument/NL/lov/ 1983-06-03-54 Accessed: 02.12.2016].

15. Brattabø IV, Iversen AC, Åstrøm AN, Bjørknes R. Experience with suspecting child maltreatment in the Norwegian public dental health services, a national survey. Acta Odontol Scand. 2016;74(8):626-32.

16. Pösö T, Skivenes M, Hestbæk A-D. Child protection systems within the Danish, Finnish and Norwegian welfare states-time for a child centric approach? Eur J Soc Work. 2014;17(4):475-90.

17. The Child Welfare Act, [https://www.regjeringen.no/en/dokumenter/thechild-welfare-act/id448398/ Accessed: 01.12.2016].

18. Mogaddam M, Kamal I, Merdad L, Alamoudi N. Knowledge, attitudes, and behaviors of dentists regarding child physical abuse in Jeddah, Saudi Arabia. Child Abuse Negl. 2016:54:43-56.

19. Uldum B, Christensen HN, Welbury R, Poulsen S. Danish dentists' and dental hygienists' knowledge of and experience with suspicion of child abuse or neglect. Int J Paediatr Dent. 2010;20(5):361-5.

20. Harris JC, Elcock C, Sidebotham PD, Welbury RR. Safeguarding children in dentistry: 1. Child protection training, experience and practice of dental professionals with an interest in paediatric dentistry. Br Dent J. 2009;206(8):409-14.

21. Montecchi PP, Di Trani M, Sarzi Amade D, Bufacchi C, Montecchi F, Polimeni A. The dentist's role in recognizing childhood abuses: study on the dental health of children victims of abuse and witnesses to violence. Eur J Paediatr Dent. 2009;10(4):185-7

22. Harris CM, Welbury $R$, Cairns AM. The Scottish dental practitioner's role in managing child abuse and neglect. Br Dent J. 2013;214(E24):1-5.

23. Newcity A, Ziniel S, Needleman $\mathrm{H}$. Recognizing and reporting child maltreatment: a survey of Massachusetts dentists. J Mass Dent Soc. 2011;60(3):20

24. Cairns AM, Mok JY, Welbury RR. The dental practitioner and child protection in Scotland. Br Dent J. 2005;199(8):517-20.

25. Kvist T, Wickstrom A, Miglis I, Dahllof G. The dilemma of reporting suspicions of child maltreatment in pediatric dentistry. Eur J Oral Sci. 2014; 122(5):332-8.

26. Laud A, Gizani S, Maragkou S, Welbury R, Papagiannoulis L. Child protection training, experience, and personal views of dentists in the prefecture of Attica, Greece. Int J Paediatr Dent. 2013;23(1):64-71.

27. Kaur H, Chaudhary S, Choudhary N, Manuja N, Chaitra T, Amit SA. Child abuse: cross-sectional survey of general dentists. J Oral Biol Craniofac Res. 2016;6(2):118-23.

28. van Dam BAFM, van der Sanden WJM, Bruers JJM. Recognizing and reporting domestic violence: attitudes, experiences and behavior of Dutch dentists. BMC Oral Health. 2015:15(1):159.

29. Uldum B, Christensen HN, Welbury R, Haubek D. How Danish dentists and dental hygienists handle their role in child abuse and neglect matters. Acta Odontol Scand. 2017;75(5):332-337. https://doi.org/10.1080/00016357.2017. 1307448.

30. Kvist T, Cocozza M, Annerbäck EM, Dahllöf G. Child maltreatmentprevalence and characteristics of mandatory reports from dental professionals to the social services. Int J Paediatr Dent. 2017;27(1):3-10. https://doi.org/10.1111/ipd.12230.

31. Park CM, Welbury R. Current and Historical Involvement of the Dentistry in Child Protection and a Glimpse of the Future. Oral Dis. 2016;22(7):605-608. https://doi.org/10.1111/odi.12485.

32. Goebbels AFG, Nicholson JM, Walsh K, De Vries H. Teachers' reporting of suspected child abuse and neglect: behaviour and determinants. Health Educ Res. 2008;23(6):941-51.

33. Walsh KM, Farrell AM, Schweitzer R, Bridgstock RS. Critical factors in teachers' detecting and reporting child abuse and neglect: Implications for practice. Final report prepared for the Abused Child Trust. Queensland: Queensland University of Technology; 2005.

34. Ananth CV, Platt RW, Savitz DA. Regression models for clustered binary responses: implications of ignoring the Intracluster correlation in an analysis of perinatal mortality in twin gestations. Ann Epidemiol. 2005:15(4):293-301.

35. Statistics Norway [www.ssb.no/en/statistikkbanken Accessed: 02.12.2016].
36. Hallberg U, Camling E, Zickert I, Robertson A, Berggren U. Dental appointment no-shows: why do some parents fail to take their children to the dentist? Int J Paediatr Dent. 2008;18(1):27-34.

37. Simons D, Pearson N, Dittu A. Why are vulnerable children not brought to their dentalappointments? Br Dent J. 2015;219(2):61-5.

38. Powell C, Appleton JV. Children and young people's missed health care appointments: reconceptualising 'Did not Attend' to 'Was not Brought' - a review of the evidence for practice. J Res Nurs. 2012;17(2):181-92.

39. Bhatia SK, Maguire SA, Chadwick BL, Hunter ML, Harris JC, Tempest V, Mann MK, Kemp AM. Characteristics of child dental neglect: a systematic review. J Dent. 2014:42(3):229-39.

40. Humphris $\mathrm{G}$, King K. The prevalence of dental anxiety across previous distressing experiences. J Anxiety Disord. 2011;25(2):232-6.

41. Bright MA, Alford SM, Hinojosa MS, Knapp C, Fernandez-Baca DE. Adverse childhood experiences and dental health in children and adolescents. Commun Dent Oral Epidemiol. 2015;43(3):193-9.

42. Schwendicke F, Dörfer C, Schlattmann P, Page LF, Thomson W, Paris S. Socioeconomic inequality and caries a systematic review and meta-analysis. J Dent Res. 2015;94(1):10-8.

43. Duda JG, Biss SP, Bertoli FMdP, Bruzamolin CD, Pizzatto E, Souza JF, Losso EM, Oral health status in victims of child abuse: a case-control study. Int J Paediatr Dent. 2017:27(3):210-216. https://doi.org/10.1111/ipd.12254.

44. Children under the care of the child welfare service. The Norwegian Directorate for Children, Youth and Family Affairs [https://www.bufdir.no/ en/English_start_page/Children_under_the_care_of_the_child_welfare_ services/ Accessed: 02.12.2016].

45. Besharov DJ. Overreporting and underreporting of child abuse and neglect are twin problems. In: Loseke DR, Gelles RJ, Cavanaugh MM, editors. Current controversies on family violence edn. Thousand Oaks: Sage Publications; 2005. p. 285-298.

46. Finkelhor D. The main problem is underreporting child abuse and neglect. In: Loseke DR, Gelles RJ, Cavanaugh MM, editors. Current controversies on family violence. edn. Thousand Oaks: Sage Publications; 2005. p. 299-310.

\section{Submit your next manuscript to BioMed Central and we will help you at every step:}

- We accept pre-submission inquiries

- Our selector tool helps you to find the most relevant journal

- We provide round the clock customer support

- Convenient online submission

- Thorough peer review

- Inclusion in PubMed and all major indexing services

- Maximum visibility for your research

Submit your manuscript at www.biomedcentral.com/submit

C) BioMed Central 